Branislav Dobrucky - Slavomir Kascak - Michal Prazenica - Roman Konarik

\title{
BASIC COMPARISON AND EVALUATION OF FUNCTIONALITY AC-AC MATRIX CONVERTER CONCEPTS FOR HEV VEHICLE: PART II
}

The paper deals with a modeling and simulation of the direct AC-AC propulsion system and compares two matrix converter concepts with five-phase traction induction motors (IM) for the hybrid electric vehicle (HEV). The simulation results of [3x5] matrix converter and 4Q-converter are done using Matlab-Simulink environment. Part I deals with a theoretical study of converter concepts for hybrid electric vehicle, since the configurations of [3x5]+[0x5] matrix converters with five-phase motor(s) have not been analyzed so far. Based on simulation results the comparison and evaluation of the property and quality of the quantities of different type of the matrix powertrain are discussed in Part II.

Keywords: AC/AC powertrain, $3 x 5$ matrix converter, 0x5 matrix converter, five-phase induction motor, electric drive, $4 Q C$ converter, modeling and simulation, HEV vehicle

The article is a continuation of Part $I$ [1].

\section{Introduction}

The paper [2] compares a [3x3] matrix converter $(\mathrm{MxC})$ and 3-phase VSI converter with an active front end for a $7.5 \mathrm{~kW}$ induction motor drive. It has been shown that the matrix converter's semiconductor losses are smaller at full load operation for the same silicon area in both converters. A one-third reduction of the device current rating of the MC is possible, resulting in comparable thermal device stress. The overall passive component count and rating are only slightly better for the $\mathrm{MxC}$ but the absence of bulky smoothing capacitor is evident what emphases also work [3].

A novel enhanced AC/AC series/parallel HEV powertrain has been introduced in Part I of [1], Figure 1.

An indirect space-vector modulated three-phase AC-DC matrix converter for hybrid electric vehicles in [4], and with improved efficiency in [5]. The configurations of $[3 \times 5]+[0 \times 5]$ matrix converters with five-phase motor(s) are not analyzed in available literature so far.

\section{Comparing simulation results of both concepts of $\mathrm{MxC}$ propulsion powertrain}

Modeling approach of PMSG generator was taken from [6] and [7]. Modeling of matrix converter with indirect control and supposing multi-phase commutation was adapted for five-phase from [8-11] without special IM control. Model of five-phase IM can be found and taken from [12]. The connection of the control scheme of
$\mathrm{AC} / \mathrm{AC}$ powertrain with internal-combustion engine and synchronous generator together with a five phase induction machine and matrix converter are depicted in Figure 2.

The simulation results of the proposed powertrain are shown in Figures 2-4. Autonomous drive mode of HEV powered by ICE/SG is shown in Figure 3a-e. It can be seen as waveforms of input/output quantities of [3x5] $\mathrm{MxC}$ as phase motor current/voltage and generator current/voltage, respectively. The entire control scheme in Matlab/Simulink environment is shown in Figure 2 - where matrix converter is presented by block $3 \times 5 \mathrm{MxC}$.

There are simulation results of the start-up of $\mathrm{AC} /$ AC powertrain in Figure 3a and 3c. After start-up of ICE/ SG during 0-2 sec with one no-load IM, the IM is loaded by torque equal $20 \mathrm{Nm}$. Steady-state results of voltages and currents of SG and IM are given in Figure $3 \mathrm{~b}$ and Figure 3d-e. They show a good quality of the quantity waveforms, mainly of phase-current of IM. Any special control of IM has not been used.

Autonomous drive mode of $\mathrm{HEV}$ powered by $\mathrm{AB}$ accu-battery using $4 \mathrm{QC}$ and [3x5] $\mathrm{MxC}$ is shown in Figure 4. Wave-forms of input/output quantities of $4 \mathrm{QC}$ and [3x5] $\mathrm{MxC}$ can be seen there.

There are results of the start-up of AC/AC powertrain powered by accu-battery and 4QC converter in Figure 4a-c and Figure $4 \mathrm{f}$-g. The total course of the start-up is similar to the previous one (in Figure 3c) but DC current is taken from accu-battery $\mathrm{AB}$ and input currents of [3x5] $\mathrm{MxC}$ are different due to $4 \mathrm{QC}$ operation. During start-up, the IM is no-loaded. The steady-state voltage of 4QC, phase-voltage, and current IM are given in Figure 4e and Figure 4h. Phasecurrent of IM (Figure 4h) is similar to that of IM powered by $\mathrm{AB}$ without 4QC (Figure 5e - the next). Any special control of IM has not been used.

\footnotetext{
Branislav Dobrucky*, Slavomir Kascak, Michal Prazenica, Roman Konarik

Department of Mechatronics and Electronics, Faculty of Electrical Engineering and Information Technology, University of Zilina, Slovakia

*E-mail of corresponding author: branislav.dobrucky@fel.uniza.sk
} 


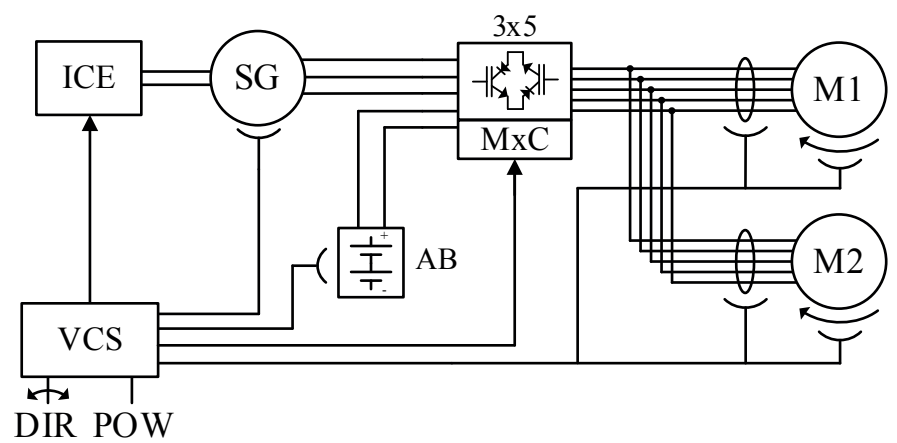

Figure 1 Novel enhanced AC/AC series/parallel HEV with one MxC converter and two traction motors M1, M2 with independent control

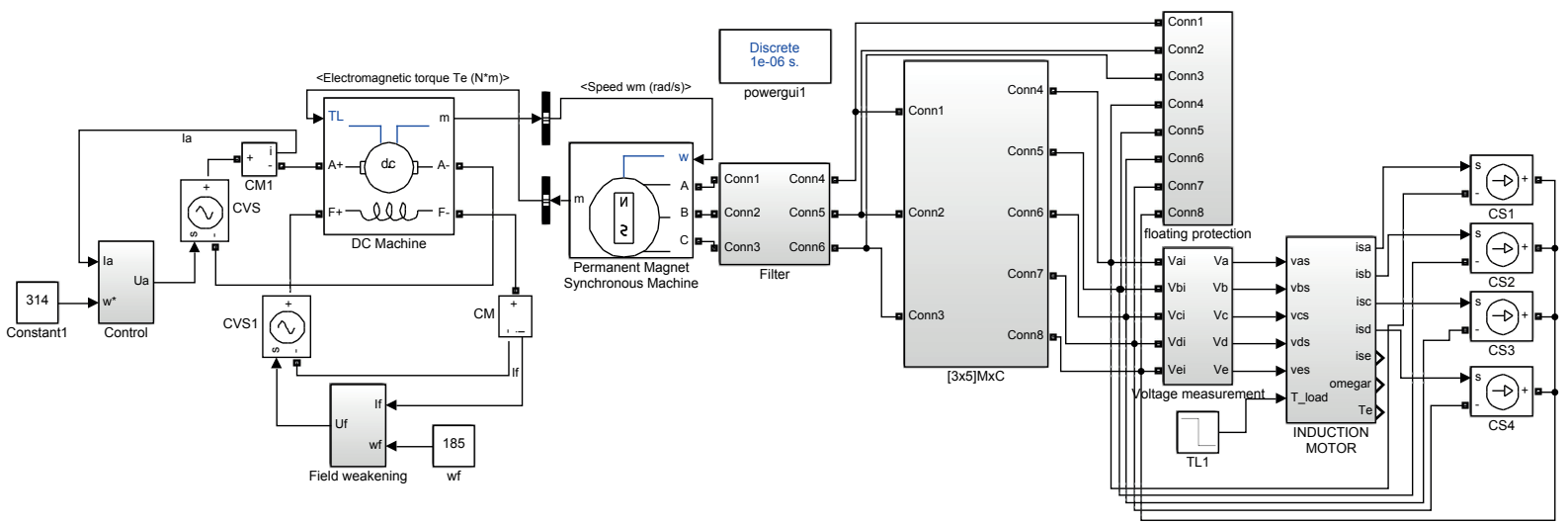

Figure 2 The control scheme of AC/AC powertrain with ICE/SG unit, [3x5] matrix converter and 5-phase IM in Matlab/Simulink environment

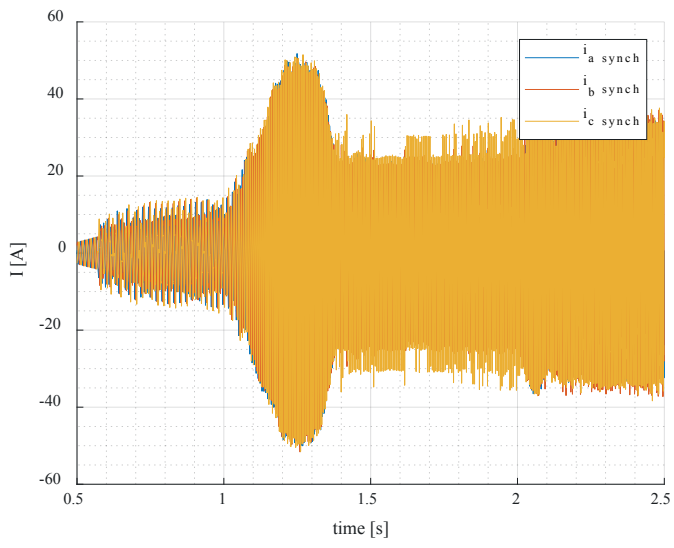

Figure 3a Start-up of SG - phase-currents

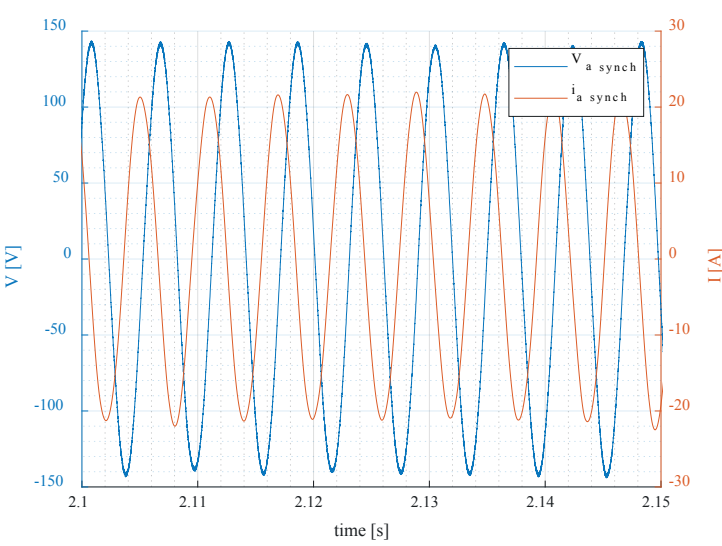

Figure $3 \boldsymbol{b}$ The $S G$ - phase-voltage/current in details

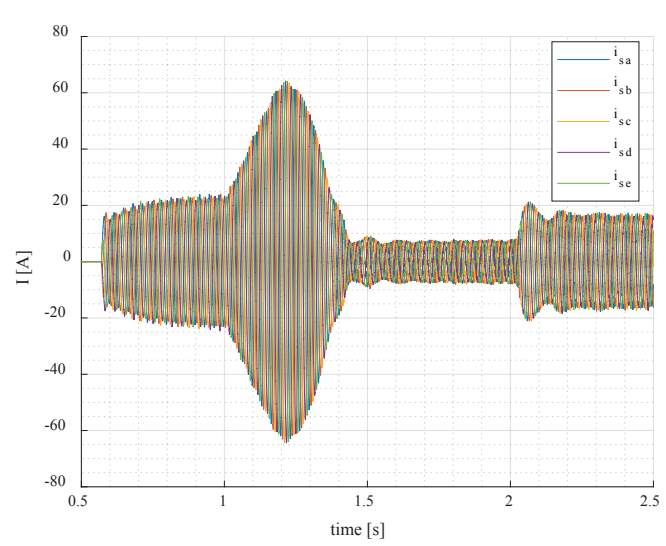

Figure 3c Start-up of IM - phase-currents

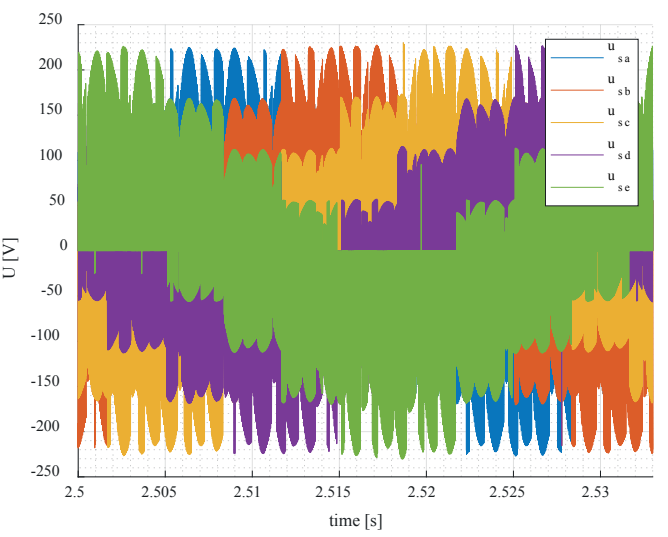

Figure 3d The IM phase-voltages of IM 


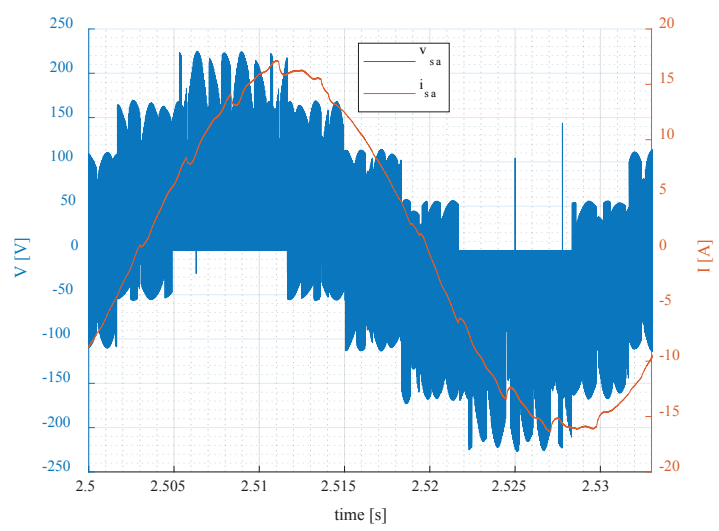

Figure $3 \boldsymbol{e}$ The IM phase-current and voltage in steady-state in detail

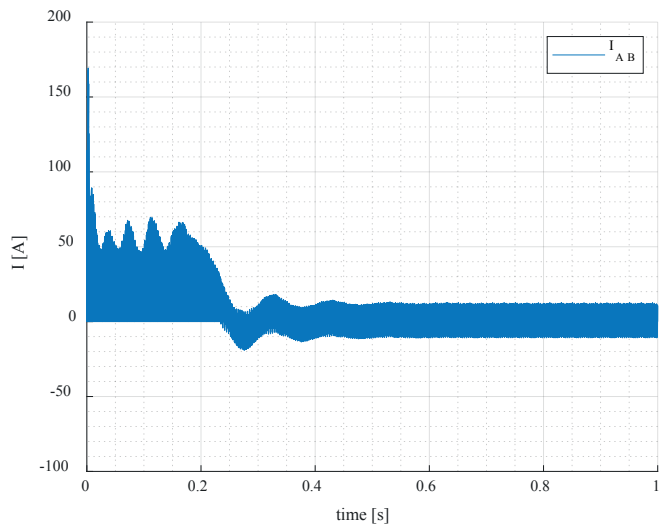

Figure 4a The current taken from accu-battery

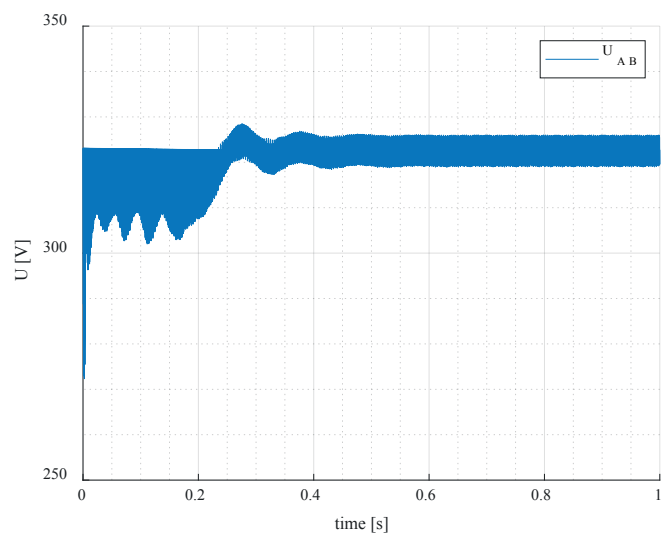

Figure $4 \boldsymbol{b}$ The accu-battery voltage

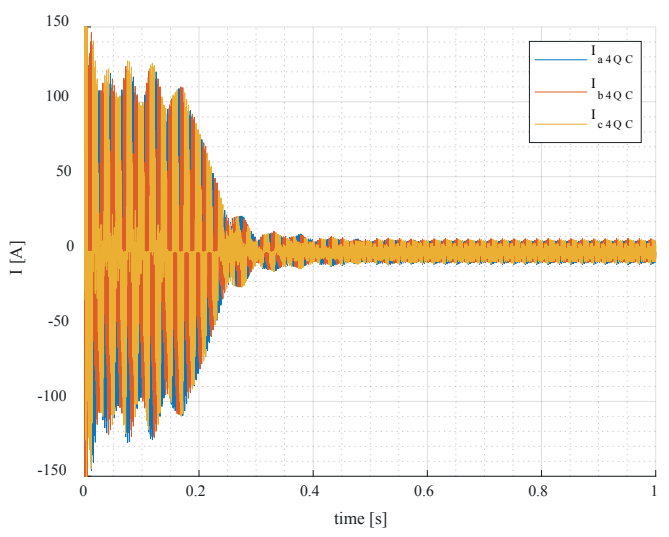

Figure 4c Start-up $4 Q C$ currents of traction mode

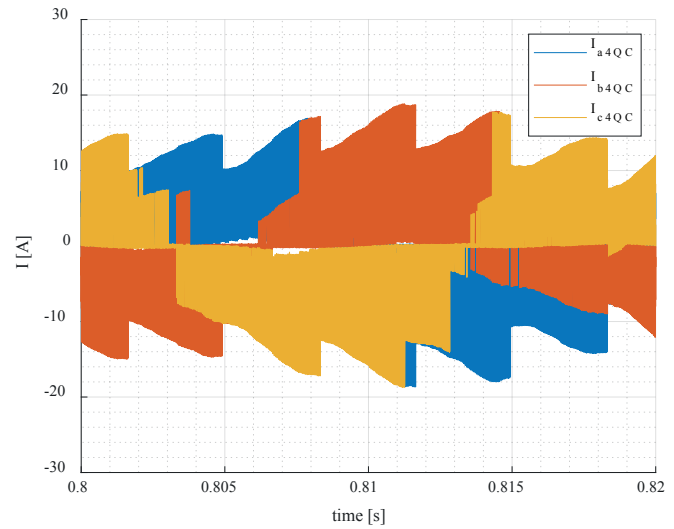

Figure $4 d$ The $4 Q C$ phase-currents in detail

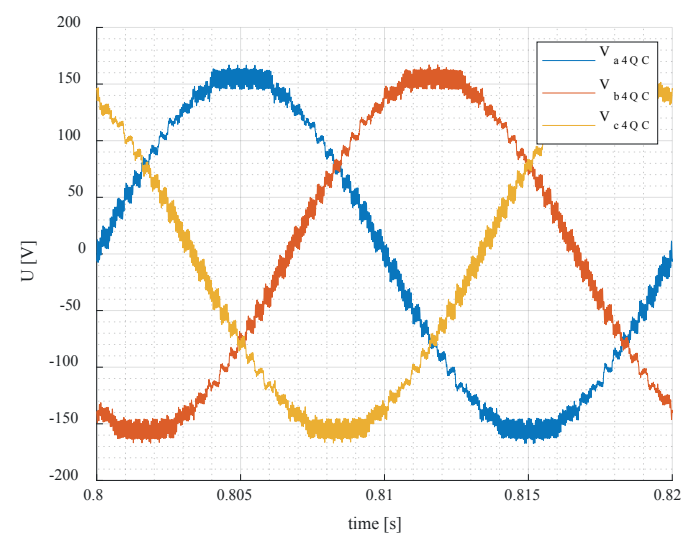

Figure 4e The $4 Q C$ phase-voltages in detail

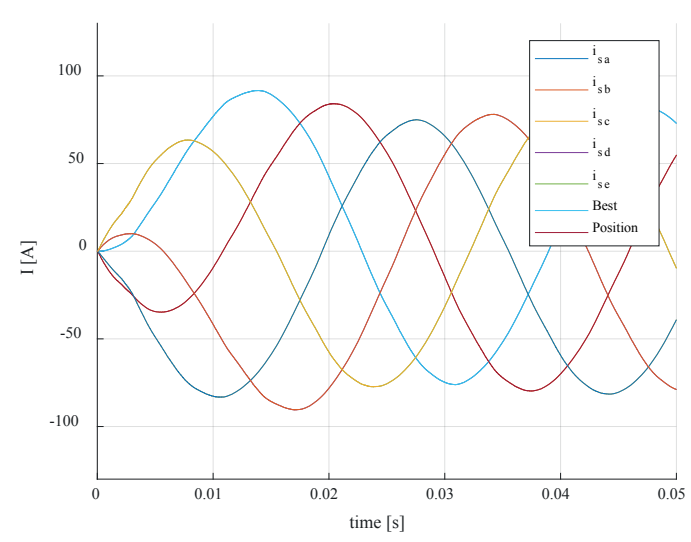

Figure 4 Start-up currents of IM 


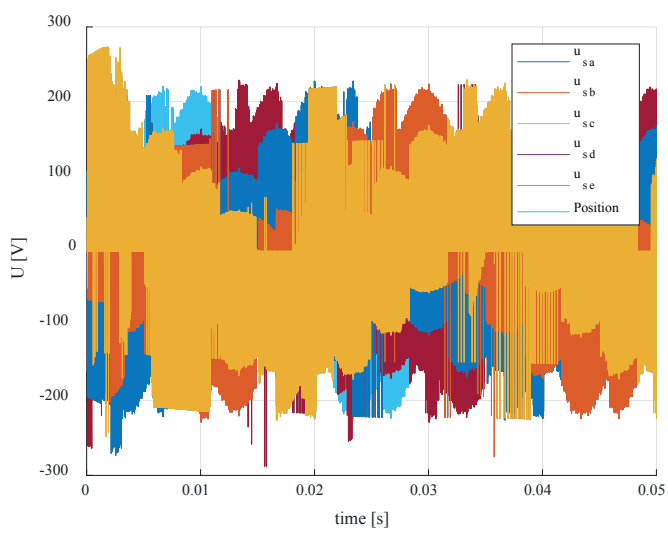

Figure $4 g$ Start-up voltages of the IM motor

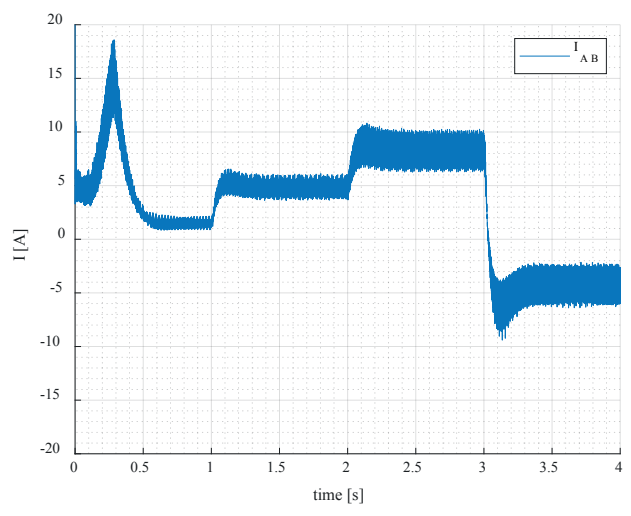

Figure 5a The current taken from $A B$ accu-battery

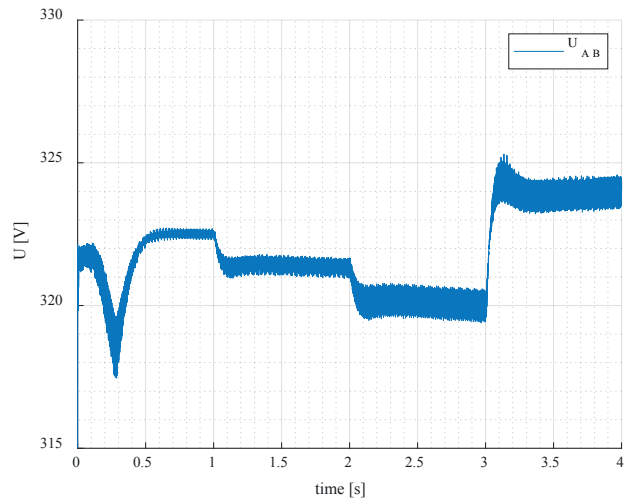

Figure $\mathbf{5 b}$ The accu-battery voltage

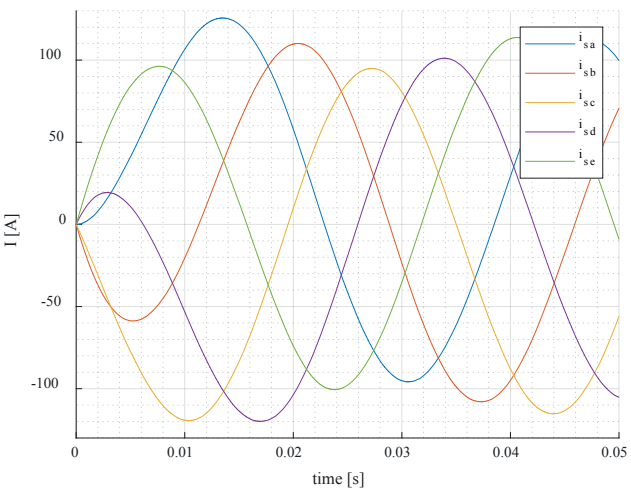

Figure 5c The stator currents in details

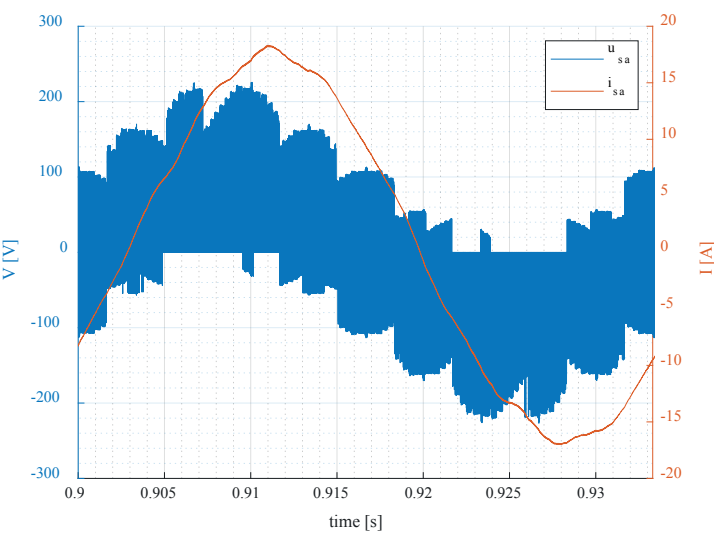

Figure 4 the phase voltage and current in detail

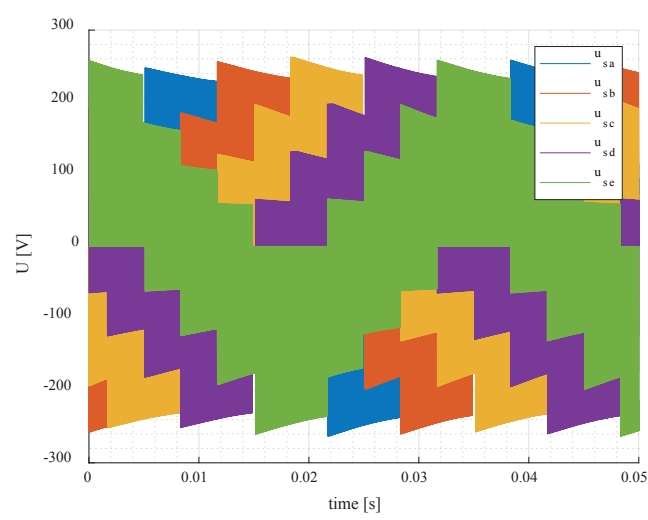

Figure 5d The stator voltages of the IM motor

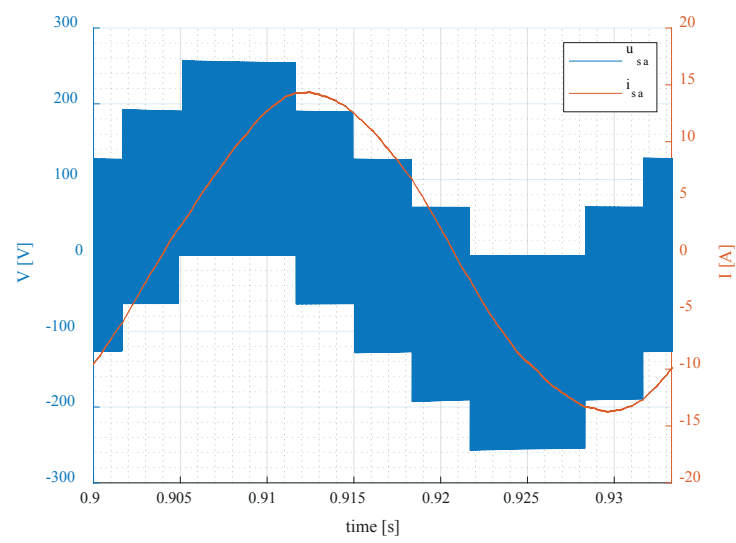

Figure 5e The phase voltage and current of the IM motor in details

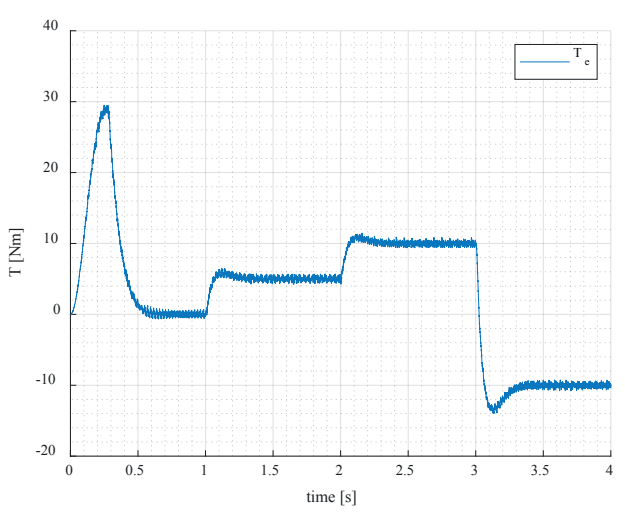

Figure $5 \boldsymbol{f}$ Time course of motor torque 


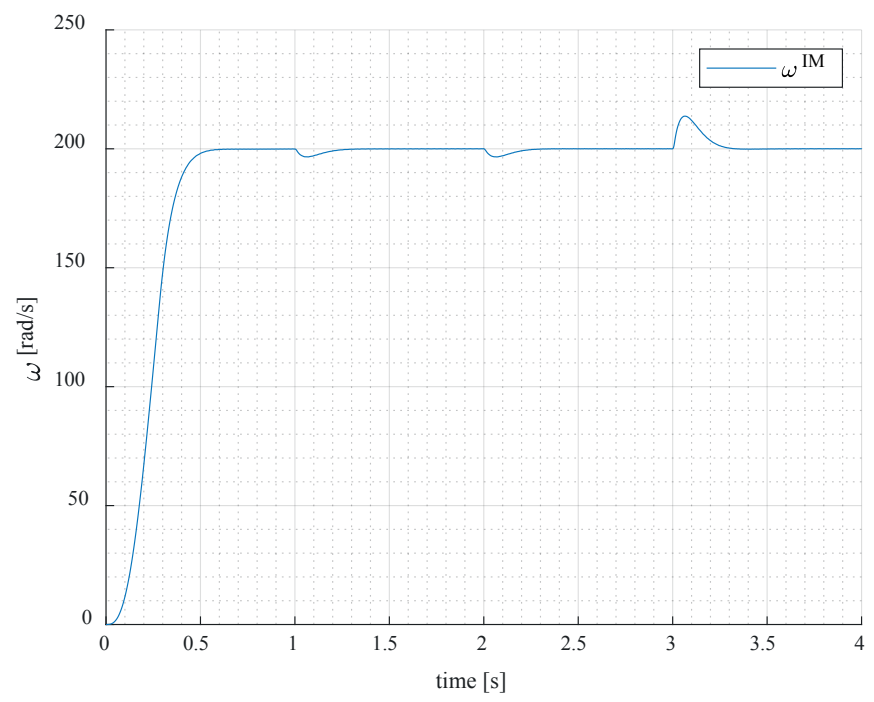

Figure 5g Time course of angular speed

Autonomous drive mode of $\mathrm{HEV}$ powered by $\mathrm{AB}$ accu-battery using [0x5] $\mathrm{MxC}$ is shown in Figure 5a-g. The waveforms of input/output quantities of [3x5] $\mathrm{MxC}$ operated as [0x5] MxC converter can be seen there.

The start-up of IM supplied by accu-battery $\mathrm{AB}$ is shown in Figure 5a, Figure 5c and Figure 5e. After start-up of ICE/SG, in time of 1, 2 and $3 \mathrm{sec}$, the IM has been loaded with torque 5, 10 and $-10 \mathrm{Nm}$, respectively. Steady-state of phase voltages and currents are presented in Figure 5d and Figure 5e. Comparison to previous result mode (Figure 4a-c) shows that start-up of IM is faster, and shape of phasevoltage of IM slightly different one but the phase-current is slighly better. Torque and angular speed circumstances are depicted in Figure 5f-g.

Comparison of autonomous modes in Figure 4 and Figure 5 shows that the concept of AC/AC powertrain with 4QC features:

worse quality of quantities waveforms as accu-battery current and output phase current and voltage of the IM motor

worse energetic efficiency because of adding of $4 \mathrm{QC}$ into the power chain.

A similar situation is regarding to charging of accubattery by concept with 4QC, and starting-up of ICE/ SG module using the 4QC unit or [0x3] and [5x3] MxCs, respectively. Comparison of autonomous modes in Figure 4 to previous Figure 2 and Figure 3 it should be noted that 4QC converter and input - 3-phase - LC filter in front of matrix converter are not necessary, therefore, the efficiency can be better.

\section{Conclusion}

Regarding comparison of [3x5] matrix converter system with auxiliary 4QC and auxiliary [0x5] MxC the second one is clearly better in the:
- battery autonomous traction and a braking regime where $4 \mathrm{QC}$ should be completed by [3x5] MxC since auxiliary [0x5] MxC should not be,

- also, charging mode from ICE/SG unit with 4QC needs either control by ICE engine or further DC/DC converter since auxiliary [0x5] MxC is not needed .

Total comparison and evaluation can be done until when all operation modes of both concepts (with 4QC and with [0x5] MxC) will be simulated and their result known. Both of those concepts make possible to also combine (parallel) modes of the HEV powertrain.

Proposed paper provides detailed study of the functionality of ac-ac matrix converter serving within the modified power train of the HEV vehicle concept. Due to high degree of complexity, the presented approach shows mostly the simulation analysis and comparison between front-end VSI propulsion system and ac-ac matrix converter system, and comparison of two variants $\mathrm{MxC}$ : with- and without $4 \mathrm{QC}$ battery converter.

Experimental verification will be realized within future research tasks based on the received results of expected behavior [13-14]. These results will be consequently published as a separate scientific paper.

\section{Acknowledge}

This work was supported by projects: APVV-15-0571 Research of the optimum energy flow control in the electric vehicle system, ITMS project No. 26210120021 co-funded from EU sources and European Regional Development Fund, and project KEGA No. 027ZU-4/2018. 


\section{References}

[1] DOBRUCKY, B., KASCAK, S., PRAZENICA, M., KONARIK, R. basic comparison and evaluation of functionality AC-AC matrix converter concepts for HEV vehicle - part I. Communications - Scientific Letters of the University of Zilina [online]. 2020, 22(1), p. 77-83. Available from: http://komunikacie.uniza.sk/index.php/communications/article/ view/1536

[2] BERNET, S., PONNALURI, S., TEICHMANN, R. Design and loss comparison of matrix converters, and voltage-source converters for modern AC drives. IEEE Transactions on Industrial Electronics [online]. 2002, 49(2), p. 304-314. ISSN 0278-0046, eISSN 1557-9948. Available from: https://doi.org/10.1109/41.993263

[3] WHEELER, P. W., CLARE, J.C., EMPRINGHAM, L. A Vector controlled MCT matrix converter induction motor drive with minimized commutation times and enhanced waveform quality. In: IEEE Industry Applications Conference : proceedings [online]. 2002. ISBN 0-7803-7420-7, ISSN 0197-2618, p. 466-472. Available from: https://doi.org/ 10.1109/LAS.2002.1044127

[4] ZHUANG, X. An indirect space-vector modulated three-phase AC-DC matrix converter for hybrid electric vehicles. Energy Procedia [online]. 2015, 75(4), p. 1968-1974. eISSN 1876-6102. Available from: https://doi.org/10.1016/j.egypro.2015.07.242

[5] DOBRUCKY, B., KASCAK, S., PRAZENICA, M., JARABICOVA, M. Improving efficiency of hybrid electric vehicle using matrix converters. Elektronika ir Elektrotechnika [online]. 2019, 25(4), p. 29-35. ISSN 1392-1215, eISSN 2029-5731 Available from: https://doi.org/10.5755/j01.eie.25.4.23967

[6] Sladecek, V., J. Drapela, P. Palacky, J. Machacek, D. Slivka, P. Hudecek . In: 11th International Scientific Conference on Electric Power Engineering, Brno, Czech Repuplic : proceedings. 2010. ISBN 978-80-214-4094-4, p. $249-252$.

[7] PowerLib Library. Matlab/Simulink. Matworks, 2017.

[8] LIVINT, G. H., HORGA, V, RATOI, M., ALBU, M. Control of hybrid electrical vehicles, electric vehicles - modelling and simulations. InTech, 2011. ISBN 978-953-307-477-1.

[9] DOBRUCKY, B., KASCAK, S., PRAZENICA, M., DRGONA, P., PAVLASEK, P. AC/AC powertrain control under different HEV supply network. 2018 ELEKTRO : proceedings [online]. IEEE, 2018. p. 2811-2823. Available from: https://doi.org/10.1109/ELEKTRO.2018.8398272

[10] JUSSILA, M., TUUSA, H. Comparison of direct and indirect matrix converters in induction motor drive. 32nd Annual Conference of the IEEE Industrial Electronics Society IECON'06 „proceedings [online]. IEEE, 2006. eISBN 978-1-50909155-3, ISSN 1553-572X, p. 1621-1626. Available from: https://doi.org/10.1109/IECON.2006.347423

[11] DOBRUCKY, B., KONARIK, R., STEFANEC, P., CHERNOYAROV, O. V. Modelling of transient phenomena of complex electrical circuits under periodic non-harmonic converter supply. Electrical Engineering-Archiv fur Elektrotechnik [online]. 2017, 99(4), p. 1429-1438. ISSN 0948-7921, eISSN 1432-0487. Available from: https://doi.org/10.1007/s00202-017-0658-4

[12] ZASKALICKY, P. Mathematical model of a five-phase pentacle connected IM supplied by a VSI inverter with PWM output voltage control. In: IEEE 27th International Scientific Conference Electronics ET 2018 : proceedings [online]. 2018. ISBN 978-1-5386-6692-0. Available from: https://doi.org/10.1109/et.2018.8549582

[13] KUCERA, L., GAJDOSIK, T., GAJDAC. I., MRUZEK, M., TOMASIKOVA, M. Simulation of real driving cycles of electric cars in laboratory conditions. Communications - Scientific Letters of the University of Zilina [online]. 2017, 19(2), p. 42-47. ISSN 1335-4205, eISSN 2585-7878. Available from: http://komunikacie.uniza.sk/index.php/communications/ article/view/210

[14] HUSAIN, I. Electric and hybrid vehicles - design fundamentals. 2. ed. CRC Press, 2011. ISBN 978143981175. 